\title{
Reservoirs and the triggering of earthquakes
}

\author{
from Peter J. Smith
}

IN spite of early doubts, it is now well established that large reservoirs can generate earthquakes. When the possibility of reservoir-induced seismicity was first mooted during the mid 1960s, it was greeted with scepticism in some quarters, largely because comparable before-andafter records for the few examples then known were unavailable. Systematic seismic surveys had only been started after impounding was under way or even, in some cases, complete; and so the details of the pre-reservoir seismic background were uncertain at best. A scientifically rigorous presentation of the evidence was therefore impossible, even though in one spectacular case (Koyna, India, 1967) a large reservoir had clearly given a relatively aseismic zone the ability to kill.

But there are no doubts now, for well documented examples of reservoirinduced seismicity are known throughout the inhabited continents. In general terms, what happens is that the huge mass of water in a reservoir changes the stress patterns in the underlying rocks. The water load exerts a simple vertical pressure on the rocks immediately, whilst the pore pressure in them increases gradually as the water infiltrates at a rate that depends on their permeability and prior water content. In addition, the water reduces the rocks' coefficient of initial friction and in the longer term can change their chemical, and hence physical, properties by weathering. Even so, it is widely held that such effects are not by themselves sufficient to generate earthquakes in zones not already subject to tectonic stress. The role of the water is rather to trigger seismic events in a highly stressed system close to break point.

This is clearly the case in the Tadjikistan region of the USSR, where the Nurek reservoir has been generating seismic activity since filling began in the early 1970s. In this, as in a number of other cases, the induced seismicity is not related directly to the absolute amount of water present but to variations in it. Bursts of seismic activity are triggered when the water level changes, the intensity of the activity increasing with the rate of level change. The temporal fluctuations in the seismicity are thus easily related to the fluctuations in the phenomenon inducing it.

The spatial distribution of the seismic activity, by contrast, is less straightforward. Most of the induced earthquakes occur beneath the central part of the reservoir and upstream (southward) from it. The region containing that half of the reservoir immediately behind the dam, on the other hand, is almost completely aseismic. Yet both the seismic and aseismic zones are lithologically similar, consisting largely of Upper Cretaceous to Palaeogene shallow-water limestones interbedded with mixed components of shale and gypsum. What, then, governs the location of the induced seismicity?

The answer, as Leith et al. have discovered (Geology 9, 440; 1981), lies in the varying structure and the different permeability regimes to which it leads. The limestone units in the region beneath the reservoir are highly fractured and thus relatively permeable, whereas the gypsum and shale units have very low permeability. The alternation of permeable and impermeable strata thus gives rise to a strongly directional overall permeability. Normal to the bedding the overall permeability is very low because the largely impermeable layers prevent, or severely restrict, water transport. Parallel to the bedding, however, the permeability is high because the water can easily diffuse along the permeable layers. In other words, in their originally horizontal configuration the strata would have prevented most vertical fluid migration.

The strata beneath the Nurek reservoir are no longer horizontal, although

Peter J. Smith is editor of 'Open Earth' and is a Reader in the Department of Earth Sciences, The Open University, Milton Keynes MK76AA, Buckinghamshire, UK. immediately upstream from the dam the effect is little different. Here the alternating layers of limestone and gypsum-shale are folded into a syncline. Any water entering one of the permeable layers could migrate to the bottom of the basin formed by that layer but would be prevented from moving any further in the vertical direction by the impermeable rock layer beneath. In this region, therefore, water cannot enter the vast mass of rock below and cannot thereby change the pore pressure. The reservoir here acts only as a load, which is insufficient to induce seismicity.

Further upstream from the dam, on the other hand, the strata are folded into a moderately plunging open anticline with the dip in the upstream direction. In this region water entering a permeable layer can diffuse along it and thus be carried to various depths without restriction. Here the pore pressure at depths does change and is sufficient to generate seismicity.

What all this amounts to in the end, of course, is yet another version of the old, old story, namely, that general geological processes governed by universal physical laws will nevertheless lead to unique consequences depending on the particular environment in which the processes take place. As far as reservoirs are concerned, it is known that the large masses of water involved can generate earthquakes; but whether and precisely where they will actually do so depends critically on local conditions.

The Nurek case shows that the pattern of induced seismicity rests upon very local conditions indeed. The lithological environment in the Nurek area is not unusually inhomogeneous on a regional scale, yet the distribution of seismic activity varies on a subreservoir scale. The obvious conclusion is that if the environmental effects of future reservoir impounding are to be predicted accurately, it will be necessary to investigate the rocks underlying the sites in no less detail. 